\title{
PERILAKU KONSUMEN DALAM MELAKUKAN KEPUTUSAN MENYEWA KAMAR HOTEL BERBINTANG UNTUK MENINGKATKAN PARIWISATA DIWILAYAH KOTAMADYA KUPANG
}

\author{
Asbi Nasar,S.ST.,MM \\ Jurusan Pariwisata, Politeknik Negeri Kupang \\ Jl. Adisucipto Kampus Penfui-Kupang NTT \\ E-mail: nasarazbii@gmail.com
}

\begin{abstract}
Abstrak
Konsumen penyewa fasilitas hunian hotel ini diperlukan adanya pengetahuan dan pemahaman terhadap perilaku konsumen dengan baik. Dimana pemasar dalam hal ini dituntut untuk memahami faktor-faktor apa saja yang menjadikan dorongan/stimulasi bagi konsumen untuk melakukan penyewaan fasilitas hunian hotel. Penelitian ini bertujuan untuk mengetahui apakah faktor kamar, makanan dan minuman, prasarana, harga, promosi, aspek eksternal dan domestik konsumen serta pelayanan menjadi pertimbangan konsumen dalam menyewa kamar hotel berbintang di Kotamadya Kupang.Penelitian dilakukan pada Hotel Aston Kupang dan Hotel Neo Eltari Kupang. Hasil penelitian berdasarkan faktor Priciple Component Analysis dan Rotasi Varimax konsumen dalam menyewa kamar hotel bintang di Kotamadya Kupang, menunjukkan bahwa total varian mencapai $65,6 \%$, sedangkan $34,4 \%$ merupakan faktor lain yang tidak termasuk dalam penelitian ini. Adapun faktor- konsumen dalam menyewa kamar hotel bintang di Kotamadya Kupang adalah faktor pelayanan 23,9\%, faktor kamar $8 \%$, faktor minuman dan makanan $6,7 \%$, faktor lokasi hotel $6,2 \%$, faktor makanan $5 \%$, faktor petugas keamanan 4,8\%, faktor informasi brosur, media cetak dan sopir 3,9\%, faktor informasi teman dan keluarga 3,7\% dan faktor air condition 3,5\%. Faktor pelayanan merupakan faktor yang dominan sebagai pertimbangan konsumen dalam menyewa kamar hotel bintang di Kotamadya Kupang.
\end{abstract}

Kata Kunci: Konsumen, menyewa kamar, pariwisata

\begin{abstract}
Hospitality business entities require comprehensive knowledge and understanding regarding consumer behaviour. Factors that drive consumers to book and use their services therefore becomes a focal emphasis in the success of hospitality business. This research aims to identify the influence of room, food and beverages, infrastructure, price, promotion, external and domestic aspects of consumers, and service, to drive consumers to book with stared-rated hotels in Kupang City. This research was conducted in Aston and Neo-EL Tari Hotels in Kupang. Research results based on Principle Component Analysis and Varimax Rotation point that the all variables predicted to $65.6 \%$ of the dependent variable, whereas the remaining $34.4 \%$ are of factors not analysed in this research. Factors influencing the booking of star-rated hotels in Kupang City are service as $23.9 \%$, room as $8 \%$, food and beverage as $6.7 \%$, hotel location as $6.2 \%$, food as $5 \%$, security personnel as $4.8 \%$, brochure information and driver as $3.9 \%$, information from friends and family as 3.7\%, and air conditioner as $3.5 \%$. It is concluded that service is the most dominant factor influencing the booking of star-rated hotels in Kupang City.
\end{abstract}

Keywords: consumer, hotel-booking, tourism

\section{PENDAHULUAN}

Perhotelan memiliki fungsi untuk menangani akomodasi bagi wisatawan, bahkan dewasa ini fungsi hotel telah semakin meningkat, di mana selain sebagai sarana penginapan, hotel juga sering digunakan sebagai tempat pertemuan-pertemuan, seminar, rapat, pesta perkawinan atau acaraacara pameran kebudayaan.

Tingkat Penghunian Kamar (TPK) Hotel berbintang di Provinsi Nusa Tenggara Timur
(NTT) pada bulan November 2015 sebesar 53,11 persen, mengalami kenaikan 1,25 poin dibanding TPK Oktober 2015 sebesar 51,86 persen. Jumlah tamu menginap pada hotel bintang bulan November 2015 sejumlah 20.353 orang dengan rincian 18.759 orang tamu nusantara dan 1.594 orang tamu mancanegara. Rata-rata lama tamu menginap di hotel berbintang pada bulan November 2015 selama 2,03 hari. Rata-rata lama tamu nusantara menginap selama 1,91 hari dan ratarata lama tamu mancanegara menginap selama 3,38 hari. Dengan meningkatkan 
industri pariwisata, perkembangan perhotelan semakin meningkat, bermunculan hotel-hotel baru pada berbagai daerah yang potensial menyerap wisatawan.

Dalam rangka memperebutkan konsumen penyewa fasilitas hunian hotel ini diperlukan adanya pengetahuan dan pemahaman terhadap perilaku konsumen dengan baik. Di mana pemasar dalam hal ini dituntut untuk memahami faktor-faktor apa saja yang menjadikan dorongan/stimulasi bagi konsumen untuk melakukan penyewaan fasilitas hunian hotel. Data BPS NTT (2016) dimana pada bulan November 2015 Tingkat Penghunian Kamar (TPK) hotel bintang di NTT sebesar 53,11 persen, hal ini berarti dari seluruh kamar hotel bintang yang tersedia di NTT pada bulan November 2015 rata-rata terisi sekitar 53,11 persen. Angka TPK bulan November 2015 meningkat 1,25 poin dari TPK bulan Oktober 2015 yang mencapai 51,86 persen. Perilaku konsumen dalam melakukan keputusan menyewa kamar hotel berbintang. Khususnya penulis berkeinginan untuk mengungkapkan faktor-faktor yang mempengaruhi konsumen tersebut dalam melakukan keputusan menyewa kamar hotel berbintang untuk meningkatkan kunjungan pariwisata di wilayah Kotamadya Kupang. Sementara Widyarini (2014) mengemukakan hasil penelitian dimana uji variabel, persepsi tamu hotel terhadap produk, tarif dan proses tidak berpengaruh terhadap keputusan tamu hotel menginap. Sedangkan iklan, lokasi, pelayanan dan sarana fisik berpengaruh terhadap keputusan tamu hotel menginap.

Hotel bintang di wilayah Kotamadya Kupang, di samping mendapat pesaing dari hotel di daerah Kodya, juga harus bersaing dengan hotel di wilayah Kabupaten Kupang. Sehingga Jumlah tamu yang menginap pada hotel bintang di Kota Kupang meningkat dari 19.642 orang pada bulan Oktober 2015 menjadi 20.353 orang pada bulan November 2015. Jumlah tamu nusantara yang menginap juga mengalami kenaikan dari 17.516 orang pada bulan Oktober 2015 menjadi 18.759 orang pada bulan November 2015. Namun, jumlah tamu mancanegara justru mengalami penurunan dari 2.126 orang pada bulan Oktober 2015 menjadi 1.594 orang pada bulan November 2015 (BPS NTT, 2016).

Rata-rata lama konsumen hotel untuk menginap pada hotel di tengah kota pada hotel bintang di kota Kupang (BPS Kota Kupang, 2016) selama bulan November 2015 mengalami sedikit kenaikan menjadi 2,03 hari dari rata-rata lama tamu menginap bulan Oktober 2015 sebesar 2,01 hari. Hal ini disebabkan pada bulan November 2015 rata- rata lama menginap tamu mancanegara mengalami kenaikan menjadi 3,38 hari dibandingkan pada bulan Oktober 2015 yang hanya selama 2,68 hari. Namun rata-rata lama menginap tamu nusantara justru mengalami sedikit penurunan menjadi 1,91 hari pada bulan November 2015 dibandingkan bulan Oktober 2015 selama 1,93 hari. Karena hotel-hotel di wilayah sekitarnya menawarkan panorama yang dekat dengan pegunungan dengan udara alamnya dan juga wisata alam, merupakan sesuatu yang menarik untuk diteliti.

Perumusan masalah dalam penelitian ini sebagai berikut "Apakah faktor kamar, makanan dan minuman, prasarana, harga, promosi, aspek eksternal dan domestik konsumen serta pelayanan menjadi pertimbangan konsumen dalam menyewa hotel berbintang di Kotamadya Kupang". Penelitian ini bertujuan untuk mengetahui apakah faktor kamar, makanan dan minuman, prasarana, harga, promosi, aspek eksternal dan domestik konsumen serta pelayanan menjadi pertimbangan konsumen dalam menyewa kamar hotel berbintang di Kotamadya Kupang.

Suhartanto, (2008) mengemukakan bahwa kepuasan konsumen selain dipengaruhi oleh kualitas pelayanan, dipengaruhi juga oleh faktor lain seperti:kualitas produk, harga, faktor situasi dan faktor pribadi konsumen.

Hasil penelitian dari Bunga Geofanny Fredeca (2010) mengemukakan bahwa variabel yang diteliti yaitu: motivasi, persepsi, pembelajaran serta sikap terhadap keputusan pembelian kembali. Sehingga tahap dalam proses pengambilan keputusan konsumen ini dipengaruhi oleh Faktor eksternal (budaya, sub budaya, kelas sosial dan kelompok referensi) serta Faktor internal/Proses psikologis ataupun perbedaan individu yaitu: motivasi, sikap, kepribadian, konsep diri, gaya hidup serta pengetahuan.

Penelitian yang dilakukan Ihshani, (2005); Hamzah \& Hariyanto, (2015); dan Priyanto, (2016) korelasi hubungan diantara kedua variabel penelitian tersebut adalah positif, maka semakin baiknya kualitas pelayanan yang diberikan oleh pengelola Ciater Spa Resort maka akan semakin meningkat pula kepuasan pengunjungnya, sebaliknya semakin buruk kualitas pelayanan yang diberikan akan berdampak terhadap semakin rendahnya kepuasan pengunjung.

Tjiptono dan Chandra (2011) menyatakan bahwa secara sederhana kualitas pelayanan adalah ukuran seberapa bagus tingkatan layanan yang diberikan mampu sesuai dengan ekspektasi pelanggan artinya kualitas pelayanan artinya kebutuhan dan keinginan 
tamu atau pengunjung yang ditentukan perusahaan

Dalam bisnis pariwisata, pelayanan menjadi dasar dan motivasi utama dari usaha yang dijalankan. Semangat melayani dengan mengutamakan kebutuhan pelanggan harus dimiliki oleh seluruh jajaran staf tanpa pandang bulu, baik itu top manajer maupun staf operasional sesuai porsi dan uraian tugas masing-masing (Hermawan, 2017)

Kertajaya, (2013) dan Tjiptono, (2015). Mengemukakan bahwa wisatawan yang tidak datang kembali merupakan bentuk ketidakpuasan terhadap pelayanan yang dilakukan pengelola. Sehingga, ketidakpuasan tersebut berdampak pada keengganan wisatawan untuk berkunjung kembali.

Priyanto (2016) mengemukakan bahwa produk yang dirasakan dengan harapannya, maka dalam menilai tingkat kepuasan dilakukan pengukuran antara kesesuaian harapan wisatawan dilayani dibandingkan dengan pelayanan nyata yang diberikan.

Karakteristik Hotel. Menurut keputusan Menteri Pariwisata, Pos dan Telekomunikasi nomor KM 94/HK.103/MPPT 87 yang dimaksud dengan hotel adalah salah satu jenis akomodasi yang menggunakan sebagian atau seluruh bangunan untuk menyediakan jasa pelayanan penginapan, makanan, dan minuman serta jasa lainnya bagi umum, yang dikelola secara komersil.

Teori Perilaku Konsumen. Perilaku konsumen bagi manajer pemasaran berfungsi sebagai dasar kegiatan penyusunan dan evaluasi strategi pemasaran (bauran pemasaran, segmentasi pasar, dan differentiation and positioning product). Tujuannya adalah mencapai target volume dan nilai pemasaran yang telah dicanangkan. Bagi manajer produksi, analisis berperan sebagai dasar penetapan kualitas dan kuantitas yang berorientasi tren terkini yang disukai oleh konsumen (Yuniarti, 2015). Sedang perilaku tindakan bahwa: "Consumer behavior may be defined as decision process and physical activity individuals engage in when evaluating, acquiring, using or disposing of good and service".

Sedangkan menurut Schiffman \& Kanuk (2007) mengemukakan tahap keluaran dalam model pengambilan keputusan konsumen menyangkut dua kegiatan pasca pembelian yang berhubungan erat yaitu perilaku pembelian dan penilaian pasca pembelian. Tujuan kedua kegiatan ini adalah untuk meningkatkan kepuasaan konsumen terhadap pembeliannya.

Menurut Kotler dan Keller (2009) Perilaku konsumen adalah "Studi tentang bagaimana individu, kelompok, dan organisasi memilih, membeli, menggunakan dan bagaimana barang, jasa, ide atau pengalaman untuk memuaskan kebutuhan dan keinginan mereka. Sehingga ada tiga variabel yang perlu diperhatikan dalam mempelajari perilaku konsumen. Tiga variabel tersebut, meliputi variabel stimulus, variabel respon dan variabel intervening (antara).

Keputusan Konsumen. Pendekatan proses pengambilan keputusan pembeli oleh konsumen menurut Schiffman \& Kanuk ( 2007) ada lima tahapan penting, yaitu : (a) Problem recognition; (b). Information search; (c) Alternative evaluation; (d) Purchase decision dan (e) Post purchase behavior

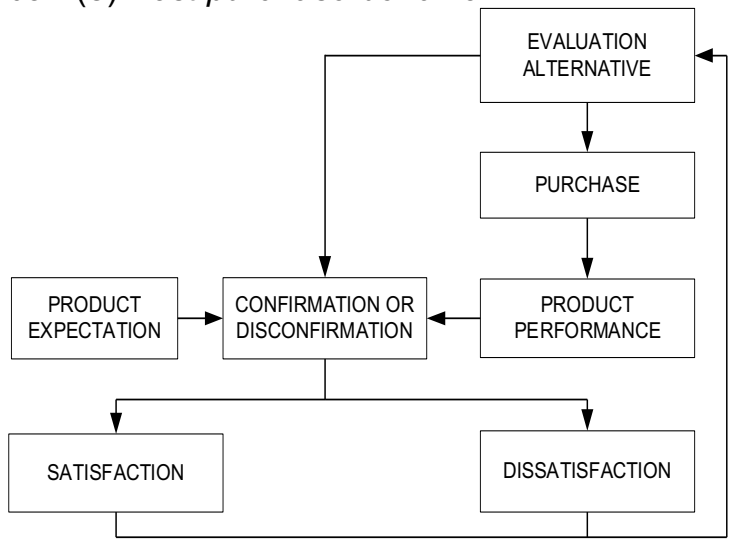

Gambar 1. Proses Evaluasi Pembelian (Schiffman \& Kanuk ( 2007)

\section{Kerangka Pemikiran Analisis}

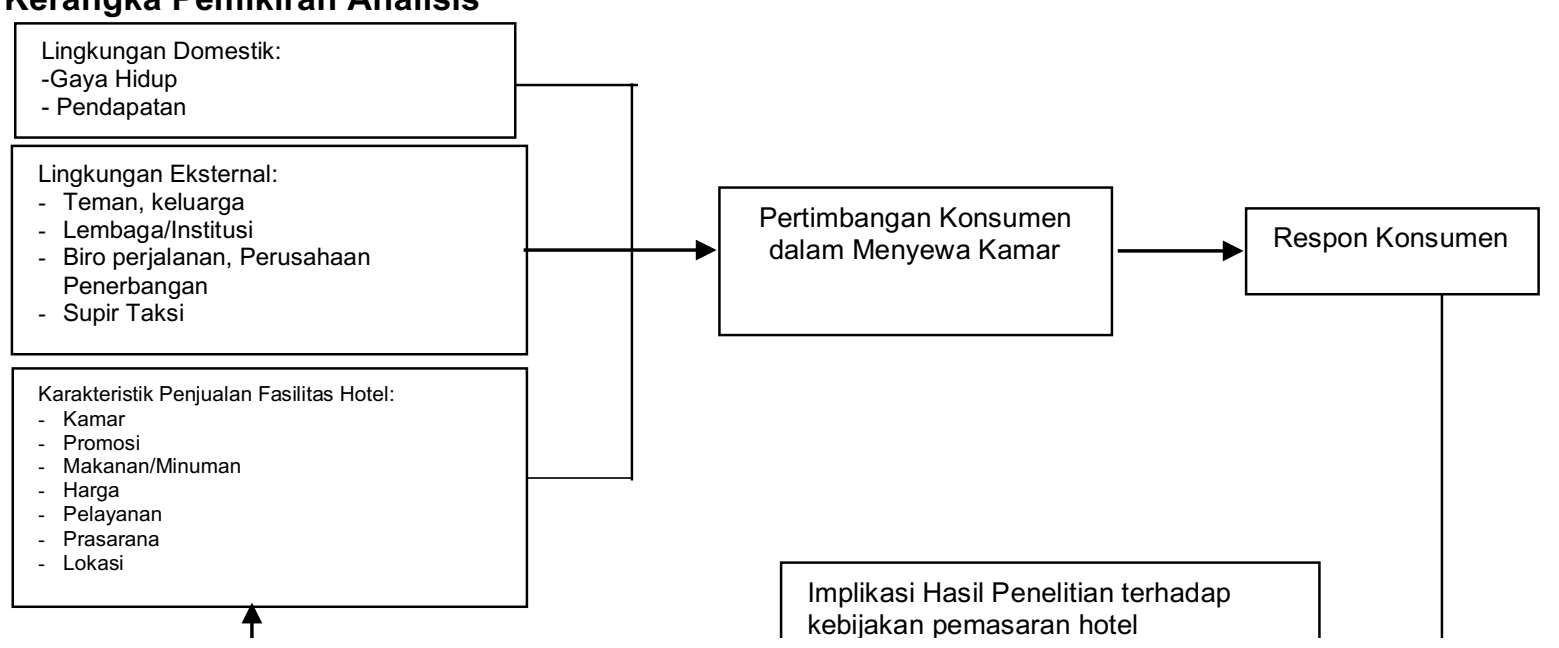


Gambar 2. Kerangka Pemikiran Analisis

\section{Hipotesis}

Berdasarkan kerangka pemikiran analisis tersebut maka hipotesis dari penelitian ini adalah : "Bahwa faktor kamar, makanan, prasarana, harga, promosi, lingkungan external dan domestik serta pelayanan menjadi pertimbangan konsumen dalam membuat keputusan menyewa kamar hotel berbintang tiga di wilayah kotamadya Kupang.

\section{METODE PENELITIAN}

\section{Ruang Lingkup Penelitian}

Berdasarkan pertimbangan yang meliputi tujuan penelitian, dana yang tersedia, waktu dan kerangka teori yang digunakan serta keterbatasan peneliti untuk mengungkap faktor-faktor yang menjadi pertimbangan konsumen dalam menyewa kamar hotel berbintang di wilayah Kotamadya Kupang, maka penelitian dilakukan pada Hotel Aston Kupang dan Hotel Neo Eltari Kupang.

\section{Teknik Sampling}

Teknik Pengambilan Sampel. Pengambilan sampel dilakukan dengan menggunakan teknik accidental sampling. Di mana responden minimal menginap pada hotel tersebut selama 1 (satu) malam pada hari kerja Selasa sampai Jumat, bulan April sampai Juli 2018. Jumlah sampel yang diambil ditetapkan sebanyak 200 responden. Jumlah ini didasarkan atas pertimbangan alat analisa yang dipilih yang mensyaratkan ketentuan sampel sebesar 4 atau 5 kali jumlah variabel yang digunakan (Sugiono, 2004).

Skala Pengukuran. Penelitian ini menggunakan skala pengukuran Likert dengan skala 5 angka, dimana angka 5 menunjukkan sangat setuju (sangat puas) sedangkan angka 1 menunjukkan sangat tidak setuju (sangat tidak puas).

Variabel yang akan digunakan dalam penelitian ini adalah sebagai berikut :

1. Variabel yang terkait dengan kamar, terdiri atas :

$\mathrm{X}_{1}=$ Air Conditions kamar $(\mathrm{AC})$

$\mathrm{X}_{2}=$ Telepon kamar

$\mathrm{X}_{3}=$ Kamar mandi

$\mathrm{X}_{4}=$ Fasilitas (rooms supplies)

$\mathrm{X}_{5}=$ Bed/tempat tidur

2. Variabel yang terkait dengan makanan dan minuman (food and beverage)

$\mathrm{X}_{6}=$ Makanan Indonesia (Indonesian foods)

$\mathrm{X}_{7}=$ Makanan China (Chinese foods)

$\mathrm{X}_{8}=$ Makanan Eropa (Europe foods)

$\mathrm{X}_{9}=$ Minuman (beverage)
3. Variabel yang terkait dengan prasarana dan kebersihan

$\mathrm{X}_{10}=$ Sarana parkir

$\mathrm{X}_{11}=$ Kolam renang

$\mathrm{X}_{12}=$ Loby hotel

$\mathrm{X}_{13}=$ Loundry

$\mathrm{X}_{14}=$ Safety box

$X_{15}=$ Bentuk bangunan

$\mathrm{X}_{16}=$ Kebersihan restoran

$\mathrm{X}_{17}=$ Kebersihan taman

$\mathrm{X}_{18}=$ Kebersihan kamar

$\mathrm{X}_{19}=$ Kebersihan kolam renang

4. Variabel yang terkait dengan pelayan

$\mathrm{X}_{20}=$ Kesopanan pelayan

$\mathrm{X}_{21}=$ Kerapihan pelayan

$\mathrm{X}_{22}=$ Tanggung jawab pelayan

5. Variabel yang terkait dengan pelayanan

$\mathrm{X}_{23}=$ Kecekatan pelayanan

$\mathrm{X}_{24}=$ Keakuratan pelayanan

$\mathrm{X}_{25}=$ Ketepatan waktu pelayanan

$\mathrm{X}_{26}=$ Keramahan pelayanan

6. Variabel yang terkait dengan lingkungan domestik

$\mathrm{X}_{27}$ = Gaya hidup

$\mathrm{X}_{28}=$ Pendapatan

$\mathrm{X}_{29}=$ Pendidikan

7. Variabel yang terkait dengan lingkungan eksternal konsumen

$X_{30}=$ Informasi teman sejawat, keluarga

$\mathrm{X}_{31}=$ Lembaga/institusi kerja

$\mathrm{X}_{32}=$ Biro perjalanan, perusahaan penerbangan

$\mathrm{X}_{34}=$ Informasi sopir taksi

8. Variabel yang terkait dengan promosi

$\mathrm{X}_{33}=$ Brosur/media cetak

9. Variabel yang terkait dengan keamanan

$\mathrm{X}_{35}=$ Rasa aman

$\mathrm{X}_{36}=$ Persiapan petugas keamanan

10. Variabel yang berkaitan dengan lokasi hotel

$\mathrm{X}_{37}=$ Kemudahan lokasi dicapai

$\mathrm{X}_{38}=$ Kemudahan dari lokasi mendapat alat transport

11. Variabel yang terkait dengan harga

$\mathrm{X}_{39}=$ Harga

$\mathrm{X}_{40}=$ Potongan harga

Alat analisa data yang digunakan dalam penelitian ini adalah analisa faktor, dimana model matematis dari analisa ini sebagai berikut :

$$
x_{i}=A_{i 1} F_{1}+A_{i 2} F_{2}+A_{i m} F_{i m}+V_{i} U_{i}
$$

Adapun langkah-langkah dalam analisa faktor adalah sebagai berikut : 


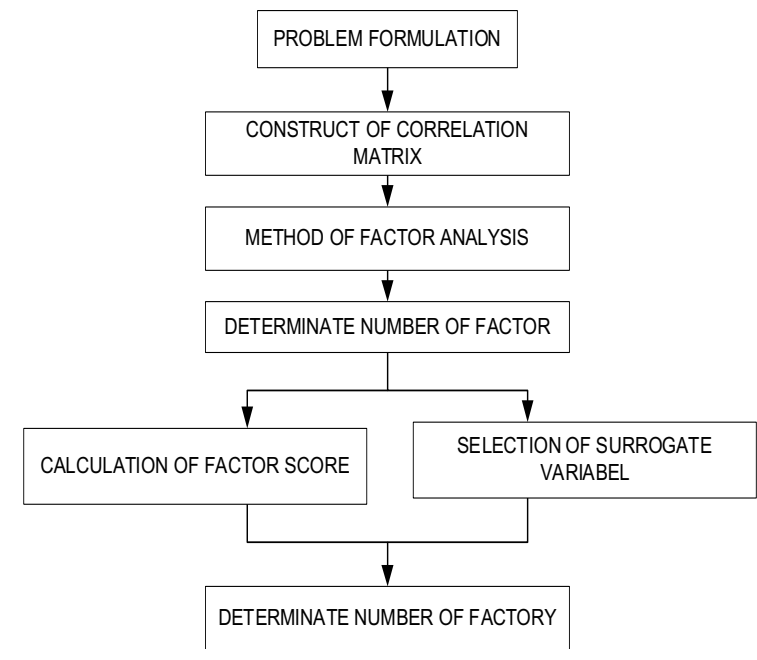

Gambar 3. Langkah-langkah Analisa Faktor (Malhotra, 1996)

\section{HASIL DAN PEMBAHASAN}

\section{Karakteristik Responden}

Karakteristik responden yang menginap pada Hotel Aston Kupang maupun Hotel Neo Eltari Kupang dalam hal ini ditinjau dari : usia, pekerjaan dan pendapatan.

\section{Usia}

Tabel 1. Jumlah Responden Menurut Kelompok Usia

\begin{tabular}{|c|c|c|}
\hline $\begin{array}{c}\text { Kelompok } \\
\text { Usia }\end{array}$ & $\begin{array}{c}\text { Jumlah } \\
\text { Responden }\end{array}$ & Persentase \\
\hline $20-29$ & 21 & 10,5 \\
$30-39$ & 57 & 28,5 \\
$40-49$ & 63 & 31,5 \\
$50-59$ & 56 & 28,0 \\
$60-69$ & 3 & 1,5 \\
\hline Jumlah & 200 & 100 \\
\hline
\end{tabular}

Sumber : Data primer

\section{Pekerjaan}

Tabel 2. Jumlah Responden Menurut Pekerjaan

\begin{tabular}{|c|c|c|}
\hline Pekerjaan & $\begin{array}{c}\text { Jumlah } \\
\text { Responden }\end{array}$ & Persentase \\
\hline Pegawai Negeri & & \\
Sipil/BUMN & 17 & 8,5 \\
ABRI & 0 & 0,0 \\
Wiraswasta & 151 & 75,5 \\
Pegawai & 32 & 16,0 \\
Swasta & & \\
\hline
\end{tabular}

\begin{tabular}{|c|c|c|}
\hline Jumlah & 200 & 100 \\
\hline
\end{tabular}

Tabel 3. Jumlah Responden Menurut Kelompok Pendapatan

\begin{tabular}{|c|c|}
\hline Kelompok Pendapatan & $\begin{array}{c}\text { Jumlah } \\
\text { Responden }\end{array}$ \\
\hline$<500.000$ & 0 \\
$500.000-<1.000 .000$ & 24 \\
$1.000 .000-<1.500 .000$ & 52 \\
$1.500 .000-<2.000 .000$ & 61 \\
$\geq 2.000 .000$ & 63 \\
\hline Jumlah & 200 \\
\hline Sumber : Data primer
\end{tabular}

Sumber : Data primer

Analisa Statistik

Tabel 4. Variabel yang Tidak Memenuhi MSA

\begin{tabular}{|c|c|}
\hline Variabel & $\begin{array}{c}\text { Measures of } \\
\text { Sampling } \\
\text { Adequacy (MSA) }\end{array}$ \\
\hline Pendapatan $\left(\mathrm{X}_{28}\right)$ & 0,38123 \\
Pendidikan $\left(\mathrm{X}_{29}\right)$ & 0,38695 \\
Biro Perjalanan $\left(\mathrm{X}_{32}\right)$ & 0,47591 \\
Ketentuan Institusi & 0,46997 \\
$\left.\mathrm{X}_{31}\right)$ & 0,47708 \\
Harga $\left(\mathrm{X}_{39}\right)$ & 0,48738 \\
Diskon Harga $\left(\mathrm{X}_{40}\right)$ & \\
\hline Sumber: Lampiran
\end{tabular}

Tabel 5. Variabel yang Tidak Memenuhi Syarat Komunalitas

\begin{tabular}{|l|c|}
\hline \multicolumn{1}{|c|}{ Variabel } & Komunalitas \\
\hline Kolam Renang $\left(\mathrm{X}_{11}\right)$ & 0,47147 \\
Kebersihan Taman $\left(\mathrm{X}_{17}\right)$ & 0,48552 \\
Kebersihan Kamar $\left(\mathrm{X}_{18}\right)$ & 0,46995 \\
Kebersihan Kolam & 0.48905 \\
Renang $\left(\mathrm{X}_{19}\right) \quad$ \\
\hline
\end{tabular}

Sumber : Lampiran

Tabel 6. Penentuan Jumlah Faktor

\begin{tabular}{|l|c|l|c|}
\hline Faktor & $\begin{array}{c}\text { Eigen } \\
\text { value }\end{array}$ & \% Varian & $\begin{array}{c}\text { Kum. } \\
\text { Varian }\end{array}$ \\
\hline Faktor 1 & 7,15984 & 23,9 & 23,9 \\
Faktor 2 & 2,41026 & 8,0 & 31,9 \\
Faktor 3 & 2,02412 & 6,7 & 38,6 \\
Faktor 4 & 1,84613 & 6,2 & 44,8 \\
Faktor 5 & 1,49007 & 5,0 & 49,8 \\
Faktor 6 & 1,42890 & 4,8 & 54,5 \\
Faktor 7 & 1,15759 & 3,9 & 58,4 \\
Faktor 8 & 1,12447 & 3,7 & 62,1 \\
Faktor 9 & 1,03966 & 3,5 & 65,6 \\
\hline
\end{tabular}

Tabel 7. Rotasi Faktor : Varimax

\begin{tabular}{|c|ll|l|c|c|}
\hline No & \multicolumn{2}{|c|}{ Variabel } & Faktor & \% Varian & Faktor Loading \\
\hline 1 & Keramahan pelayanan & $\left(\mathrm{X}_{26}\right)$ & & & 0,78667 \\
2 & Kesopanan pelayan & $\left(\mathrm{X}_{20}\right)$ & & & 0,78008 \\
3 & Tanggung jawab pelayan & $\left(\mathrm{X}_{22}\right)$ & Pelayanan & \multirow{2}{*}{23,9} & 0,61196 \\
4 & Kecekatan pelayanan & $\left(\mathrm{X}_{23}\right)$ & & & 0,56027 \\
5 & Keakuratan pelayanan & $\left(\mathrm{X}_{24}\right)$ & & & 0,52748 \\
6 & Kerapihan pakaian pelayan & $\left(\mathrm{X}_{21}\right)$ & & & $0,48869^{\star}$ \\
\hline
\end{tabular}




\begin{tabular}{|c|c|c|c|c|c|}
\hline 7 & Kamar mandi & $\left(\mathrm{X}_{3}\right)$ & & & 0,74801 \\
\hline 8 & Fasilitas (room supplies) & $\left(X_{4}\right)$ & & & 0,73564 \\
\hline 9 & Telepon kamar & $\left(X_{2}\right)$ & & & 0,72021 \\
\hline 10 & Tempat tidur & $\left(X_{5}\right)$ & Fasilitas & 8,0 & 0,66673 \\
\hline 11 & Safety box & $\left(X_{14}\right)$ & Kamar & & 0,57051 \\
\hline 12 & Laundry & $\left(X_{13}\right)$ & & & $0,49431^{*}$ \\
\hline 13 & Desain Gedung & $\left(X_{15}\right)$ & & & $0,42599^{*}$ \\
\hline 14 & Kebersihan Restoran & $\left(X_{16}\right)$ & & & $0,38761^{*}$ \\
\hline 15 & Minuman & $\left(X_{9}\right)$ & $\begin{array}{l}\text { Minuman } \\
\text { dan }\end{array}$ & & 0,70714 \\
\hline 16 & Makanan Indonesia & $\left(X_{6}\right)$ & Makanan & 6,7 & 0,67814 \\
\hline 17 & Sarana parkir & $\left(X_{10}\right)$ & & & 0,61546 \\
\hline 18 & Ketepatan waktu pelayanan & $\left(X_{25}\right)$ & & & $0,39837^{*}$ \\
\hline 19 & Kemudahan transportasi & $\left(\mathrm{X}_{38}\right)$ & Lokasi & 6,2 & 0,89406 \\
\hline 20 & $\begin{array}{l}\text { Kemudahan menemukan } \\
\text { lokasi }\end{array}$ & $\left(X_{37}\right)$ & & & 0,89370 \\
\hline 21 & Makanan Eropa & $\left(\mathrm{X}_{8}\right)$ & Makanan & 5,0 & 0,77682 \\
\hline 22 & Makanan China & $\left(X_{7}\right)$ & $\begin{array}{l}\text { Eropa dan } \\
\text { China }\end{array}$ & & 0,74980 \\
\hline 23 & Kesiapan petugas keamanan & $\left(\mathrm{X}_{36}\right)$ & Kesiapan & & 0,83156 \\
\hline 24 & Gaya hidup & $\left(X_{27}\right)$ & Petugas & 4,8 & 0,67865 \\
\hline 25 & Keamanan/ rasa aman & $\left(X_{35}\right)$ & Keamanan & & $0,48942^{*}$ \\
\hline 26 & $\begin{array}{l}\text { Informasi brosur dan media } \\
\text { cetak }\end{array}$ & $\left(X_{33}\right)$ & $\begin{array}{l}\text { Informasi } \\
\text { Media }\end{array}$ & & 0,77403 \\
\hline 27 & Informasi sopir taksi & $\left(\mathrm{X}_{34}\right)$ & $\begin{array}{l}\text { Cetak, } \\
\text { Brosur }\end{array}$ & 3,9 & 0,75569 \\
\hline 28 & Lobi hotel & $\left(\mathrm{X}_{12}\right)$ & $\begin{array}{c}\text { dan Sopir } \\
\text { Taksi }\end{array}$ & & $0,49108^{*}$ \\
\hline 29 & Informasi teman, keluarga & $\left(\mathrm{X}_{30}\right)$ & $\begin{array}{l}\text { Informasi } \\
\text { Teman \& } \\
\text { Keluarga }\end{array}$ & 3,7 & 0,73607 \\
\hline 30 & Air Condition & $\left(\mathrm{X}_{1}\right)$ & A.C & 3,5 & 0,70724 \\
\hline
\end{tabular}

* faktor loading tidak memenuhi syarat.
famper: Lampiran

\section{Interpretasi}

Interpretasi hasil analisa faktor ini mengacu pada rotasi faktor yang telah dilakukan di mana dari 30 variabel yang ada tersebar ke dalam 9 faktor dengan total varian sebesar 65,6 persen. Syarat kecukupan total varian adalah $60 \%$ (Malhotra, 1996). Sehingga dari 9 faktor tersebut mampu menjelaskan sebesar 65,6 persen dari berbagai pertimbangan konsumen dalam menyewa kamar hotel berbintang di Kotamadya Kupang. Sedang $\mathrm{KMO}=, 78764$ dan Bartlett Sign = 0,0000 .

Adapun 9 faktor sebagaimana pada Tabel 7 yang memenuhi syarat Eigen value tersebut adalah faktor-faktor : (pelayanan), (kamar dan safety box), (minuman dan makanan Indonesia), (lokasi hotel), (makanan Eropa dan China), (petugas keamanan), (informasi media cetak dan brosur dan sopir taksi), (informasi teman dan keluarga) dan (Air Condition).

Implikasi Hasil Penelitian

Faktor Pelayanan. Secara operasional area pelayanan dari usaha hotel yang langsung berhubungan dengan tamu dalam hal ini harus diperhatikan. Area pelayanan yang langsung berhubungan dengan tamu atau "front of the house areas" antara lain pelayanan yang meliputi : bagian pemesanan, bagian resepsionis, bagian restoran, room service, uniform service, operator telepon maupun bagian kasir.

Faktor Fasilitas Kamar. Faktor fasilias kamar ini meliputi variabel-variabel : kamar mandi, fasilitas (rooms supplies), telepon kamar, tempat tidur dan safety box. Kamar mandi, dalam hal ini menyangkut kelancaran air kamar mandi, tersedianya kelengkapan kamar mandi, kran yang baik, bath up yang baik, merupakan sarana yang dibutuhkan konsumen untuk membersihkan diri.

Faktor Minuman dan Makanan Indonesia. Memberikan gambaran bahwa para tamu hotel mempertimbangkan minuman, makanan Indonesia dan juga sarana parkir yang disediakan pihak hotel. 
Faktor Lokasi. Terdiri atas variabel-variabel kemudahan transportasi dan kemudahan menemukan lokasi hotel. Kemudahan transportasi artinya para tamu hotel dengan mudah akan mendapatkan alat transportasi dari lokasi hotel, sedang kemudahan menemukan lokasi hotel artinya para tamu dengan mudah akan dapat menemukan hotel.

Faktor Makanan Eropa dan China. Makanan merupakan variabel yang menjadi pertimbangan para tamu. Untuk itu pengelolaan makanan ini baik itu meliputi : pembelian bahan, pengelohan, standarisasi menu, penyajian dan pengendalian produksi harus diperhatikan oleh manajemen agar penyajian dan kualitas produk tetap terjaga dan senantiasa memuaskan para tamu yang menjadi konsumen hotel.

Petugas Keamanan. Terdiri atas variabel kesiapan petugas keamanan. Kesiapan petugas keamanan merupakan variabel yang dipertimbangkan oleh konsumen. Kesiapan petugas keamanan pada setiap saat akan memberikan kesan kepada para tamu yang menjadi konsumen hotel merasa keamanan hotel yang bersangkutan diperhatikan. Dengan demikian konsumen dapat lebih merasa tenang dengan keberadaan petugas keamanan.

Faktor Informasi Brosur/Media Cetak dan Sopir Taksi. Variabel brosur/media cetak ini menyangkut penyajian informasi yang jelas, desain serta kemudahan informasi ditemukan. Hubungan kerja sama dengan sopir taksi untuk menjadikannya salah satu sumber informasi yang efektif ini dapat dilakukan dengan banyak cara. Misalnya, mengijinkan taksi melakukan parking pada wilayah perhotelan, mensponsori adanya lomba sopir taksi teladan atau hal-hal lain yang menyangkut hubungan kerja sama dengan sopir taksi.

Faktor Informasi Teman dan Keluarga. Terdiri satu variabel yaitu informasi teman dan keluarga. Informasi teman dan keluarga merupakan informasi dari lingkungan eksternal konsumen yang dekat.

Faktor Air Condition. merupakan salah satu pertimbagan konsumen dalam menyewa kamar hotel bintang tiga. Manajemen harus memperhatikan Air Conditions ini dengan sebaik-baiknya.

\section{PENUTUP}

\section{Simpulan}

Berdasarkan hasil dan pembahasan maka kesimpulan dari hasil penelitian ini adalah sebagai berikut: a Dengan menggunakan analisa faktor Priciple Component Analysis (PCA) dan Rotasi Varimax terhadap berbagai pertimbangan konsumen dalam menyewa kamar hotel bintang di Hotel Aston Kupang dan Hotel Neo Eltari Kupang, menunjukkan bahwa total varian mencapai $65,6 \%$. Artinya bahwa variabel-variabel yang diteliti mampu menjelaskan 65,6 persen dari berbagai pertimbangan konsumen dalam menyewa hotel bintang di Kotamadya Kupang, sedangkan sisanya $34,4 \%$ merupakan faktor lain yang tidak termasuk dalam penelitian ini. Adapun secara berturut-turut sumbangan faktor-faktor yang menjadi pertimbangan konsumen dalam menyewa kamar hotel bintang di Kotamadya Kupang adalah sebagai berikut : Pertama adalah faktor pelayanan $(23,9 \%)$, kedua adalah faktor kamar $(8 \%)$, ketiga adalah faktor minuman dan makanan Indonesia $(6,7 \%)$, ke empat adalah faktor lokasi hotel $(6,2 \%)$, ke lima adalah faktor makanan (5\%), ke enam adalah faktor petugas keamanan $(4,8 \%)$, ke tujuh adalah faktor informasi brosur, media cetak dan sopir $(3,9 \%)$, ke delapan adalah faktor informasi teman dan keluarga $(3,7 \%)$ dan kesembilan adalah faktor air condition $(3,5 \%)$.

b Faktor pelayanan merupakan faktor yang dominan sebagai pertimbangan konsumen dalam menyewa kamar hotel bintang di Kotamadya Kupang. Dengan demikian jasa penginapan hotel sebagaimana industri jasa lainnya memiliki atribut yang utama berupa pelayanan.

c Strategi pemasaran dengan melalui marketing mix bagi industri jasa terutama hotel mewah bagi kalangan bisnis, komponen harga merupakan komponen yang kurang relevan. Sedangkan komponen product, promotion dan place merupakan komponen yang relevan dan harus diperhatikan

\section{Saran}

Kepada manajemen hotel, terutama pihak manajemen hotel bintang di wilayah Kotamaya Kupang, disarankan melakukan perhatian yang sungguh-sungguh terhadap kualitas pelayanan para pelayan hotel terutama yang langsung berhubungan dengan konsumen hotel. Manajemen hotel juga harus memperhatikan sumber daya manusia pada kantor depan hotel (the front of the house areas)

\section{DAFTAR PUSTAKA}

Bunga Geofanny Fredeca dan Chairy, 2010. Pengaruh Psikologi Konsumen Terhadap 
Keputusan Pembelian Kembali

Smartphone Blackberry, Jurnal

Manajemen Teori dan Terapan, Tahun 3, No. 2 Agustus 2010.Universitas Tarumanegara

BPS NTT, 2016, Berita Resmi Statistik, Sensus Ekonomi, No. 04/01/53/Th.XIX, 04 Januari 2016, Nusa Tenggara Timur

Hamzah, F., \& Hariyanto, O. I. B. 2015. Pengaruh Pelayanan Prima terhadap Loyalitas Tamu Menginap di Sumber Alam Resort Garut. Jurnal Pariwisata, 2(2), 8997

Hermawan, H.,2017/ Pengantar Manajemen Hospitality. Penerbit NEM Jawa Tengah:

Ihshani, D. W. 2005. Analisis Kepuasan Konsumen Terhadap Atribut Wisata Cangkuang Garut, IPB (Bogor Agricultural University), Jawa Barat.

Kertajaya, H. (2013). Tourism Marketing 3.0. PT Gramedia Pustaka Utama, Jakarta

Kotler, Philip dan Kevin Lane Keller. 2009. Manajemen Pemasaran, Edisi ke 13. Terjemahan oleh Benyamin Molan. PT Indeks. Jakarta.

Malhotra, N. K. 1996. Marketing Research, Applied Orientation. Second Edition Prentice Hall. Englewood Aliffs. New Jersey.

Priyanto, R. 2016. Pengaruh Kualitas Pelayanan terhadap Kepuasan dan Loyalitas Pengunjung Saung Angklung Udjo. Jurnal Pariwisata, 3(1), 29-40.

Schiffman, Leon.G dan Leslie Lazar Kanuk. 2007. Perilaku Konsumen. Edisi ke 7. Terjemahan oleh Drs. Zulkifli Kasip. PT Indeks. Jakarta

Sugiyono. (2004). Metode Penelitian Kombinasi.: CV Alfabeta. Bandung

Suhartanto.D. 2008. Perilaku Konsumen (Tinjauan Aplikasi di Indonesia). Penerbit: Guardaya Intimarta. Bandung

Tjiptono, F., \& Chandra, G. (2011). Service, Quality and Satisfaction. Andi Offset. Yogyakarta:

Widyarini (2014) variabel yang mempengaruhi Keputusan Pemilihan hotel syariah, Jurnal Ekbisi, Vol IX, No.1 Desember 2014, ISSN 1907-0109 